\title{
ARCHITECTURAL PRECAST FAÇADE CONSTRUCTION FOR HIGH RISE BUILDINGS - CONSTRUCTION METHOD APPROACH
}

\author{
S. Madhu Anand ${ }^{1}$ \\ ${ }^{1}$ Head-Construction Methods Planning Centre, Residential Buildings and Factories, L\& T Construction
}

\begin{abstract}
Every High rise building is unique in nature. Approach towards high rise building with $162 \mathrm{~m}$ of architectural precast element is also need innovative construction methodology. The project BNRI URBANA is the tallest building $162 \mathrm{~m}$ located in the eastern India with precast as architectural features. This is the first of its kind in India with precast elevation façade panels for $162 \mathrm{~m}$. The structure being a shear wall construction, it was difficult to accommodate with different architectural feature along with structure construction. Hence precast technology has been adopted to meet the elevation requirements. The methodology planning has become more challenging as the height of the building was $162 \mathrm{~m}$ for 7 Towers with building plan of shape Z, H with 12000 nos of Architectural precast elements with stringent delivery period. Planning construction methods for such a project requires selection of equipment, logistic planning, adoption of proper technology to meet the time, cost without compromising quality and safety. This Paper mainly focus on the construction methodology adopted to complete the above requirement with proper planning, design, casting, curing, handling, transportation, connection and erection methods.
\end{abstract}

Keywords: Precast Planning, Casting, Handling, and Erection

\section{INTRODUCTION}

Bengal NRI Complex Limited (BNRI) is a joint sector company between the government of West Bengal and a consortium of entrepreneurs in Kolkata. The Township of Urbana is being designed to fulfil the most luxurious living standards and needs. The project is spread over 66 acres of land, with seven high rise residential towers, located in the midst of open wetlands and green surroundings for unsurpassed vistas of nature and peace in the heart of the city - less than a kilometer from eastern metropolitan bypass at the ruby park crossing.

\subsection{Project Brief}

The Project URBANA Integrated Township for M/s. Bengal NRI Complex Limited is located at Anandapur, Kolkata consists of Seven Towers. The project has been divided into two phases. Phase-I consist of 4 Towers and Phase II consist of 3 Towers. All the towers are cladded with precast panels.

Client: - M/s. Bengal NRI Complex Limited.

Architect: -aCTa International Pte Ltd, Singapore

Structural Consultant: -Predrag Eror, UAE Dubai

Integrated Engineering: - Meinhardt (Singapore) India Branch.

Landscape Architect: - M/s. Green Architects Company Limited.
$* * *$

\subsection{Highlights of Building}

No.of Buildings : 7 nos

Total Buit up Area - 371750 Sqm

Plan Size - 43m x 27.2m

Height-(+)137.20m to $162 \mathrm{~m}$ above GL

No.of Storeys - 40 to 45

Structural System - Shear Wall

Architectural Façade - Precast

\section{CHALLENGES}

To construct architectural features for a building height of $162 \mathrm{~m}$ with 48 different configuration of element, the type of connection varies depends on the location in the structure which made us to adopt different methodology for erection.

The architects are firm on the shape of the profile as the elements brings aesthetic appearance of the building. This 
has made more complication in matching the groove, staggered elevation for entire height with type of element varies with elevation. The Plan of the building is in $\mathrm{Z} \& \mathrm{H}$ shape, locating the equipment was difficult as maximum weight of element was at corner of the building.

The challenges faced to meet the above construction are stated below,

$>$ Connection details based on the face of the structure

$>$ Working platform for Straight and corner panel erection

$>$ Erection of elements as the working platform of structure construction were hindering

$>$ Selection of equipment

\section{METHODOLOGY PLANNING}

Detailed planning at the pre-production stage is essential to ensure a safe and successful manufacturing, supply and erection process for a precast concrete system. The manufacturing programme and resources has been synchronized and optimized so that the delivery rate matches the project construction requirements with the required buffer stock at site. In line with the same, a detailed precast planning has been done for the project as below.

\subsection{Precast Element Layout}

Precast element layouts are the basic data for planning of precast structures. Weight of Precast panels are planned to meet the maximum available tip capacity of the tower crane. The details of precast elements per Tower are listed below.

\begin{tabular}{|l|l|c|}
\hline Sl.no & Towers & Number of Elements \\
\hline 1 & T1 & 1420 \\
\hline 2 & T2 & 2079 \\
\hline 3 & T3 & 2079 \\
\hline 4 & T4 & 1718 \\
\hline 5 & T5 & 1598 \\
\hline 6 & T6 & 1598 \\
\hline 7 & T7 & 1522 \\
\hline & Total & 12014 \\
\hline
\end{tabular}

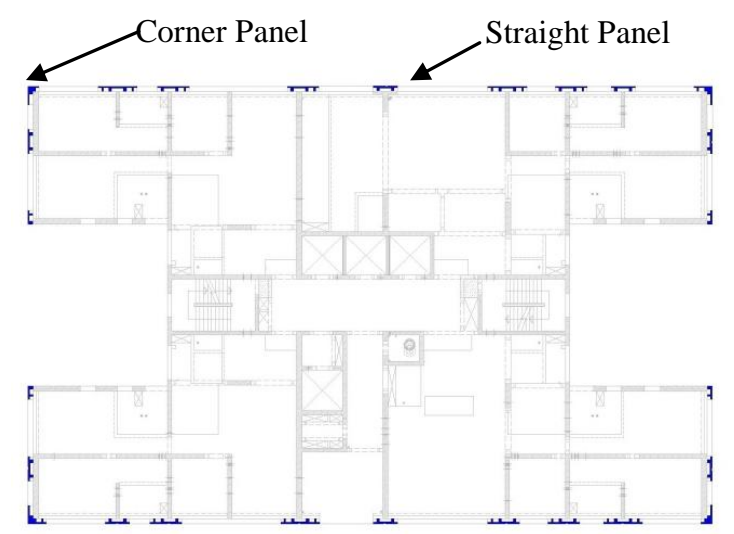

Fig -1: Typical Precast Façade Layout - H Shape Building

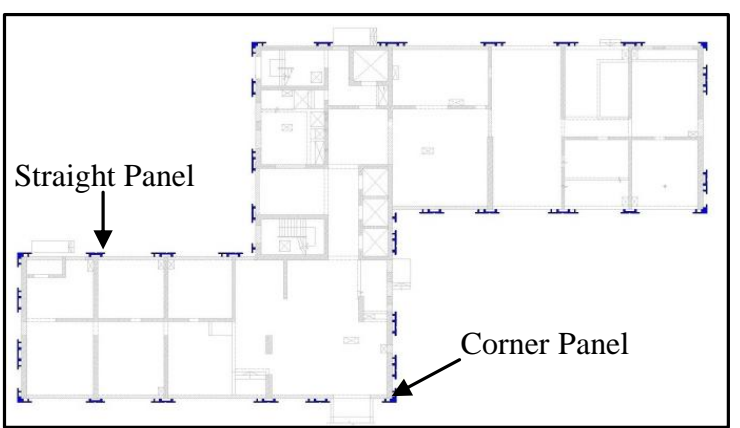

Fig -2: Typical Precast Façade Layout - Z Shape Building
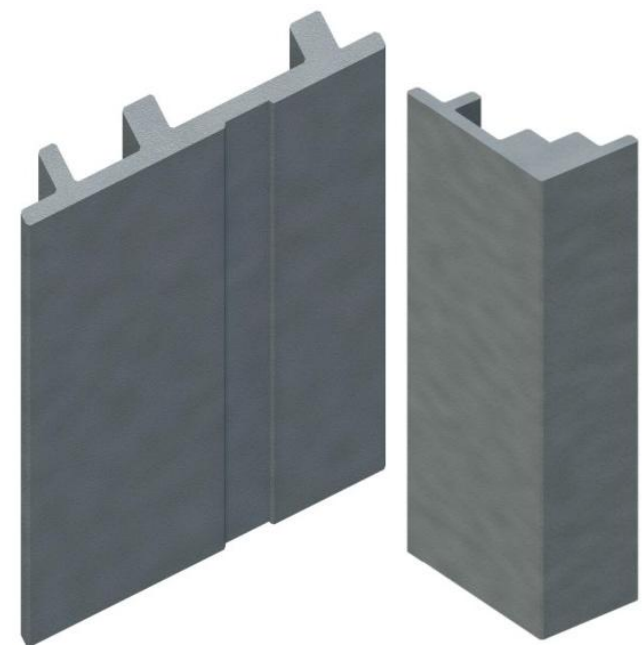

Fig -3: Typical Precast Façade - Straight\& Corner
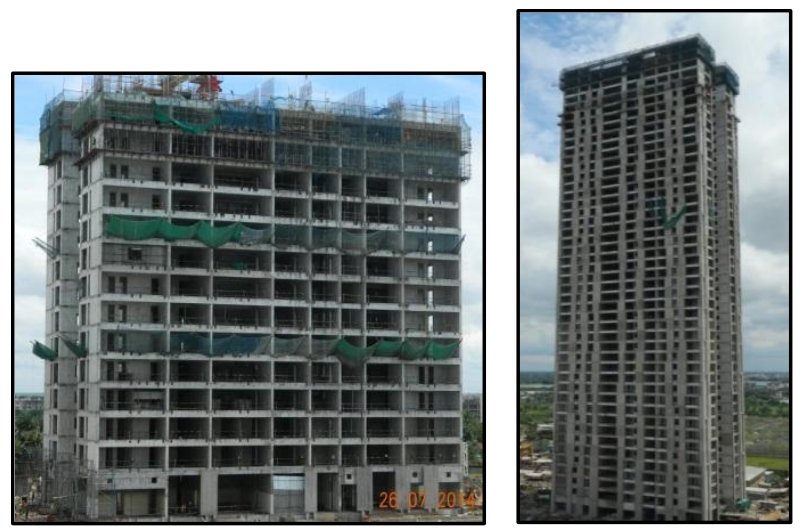

Fig- 4: Towers - Without\& With Precast Panels

\subsection{Precast Yard}

All precast elements are erected at site are supplied from a strategically located precast yard within the site premises. The precast yard has been planned such a way that the right element to be supplied at site in right time to maintain the progress of work. Thus the accurate precast yard planning becomes the back bone for the success of the project.

Total no.of Precast element for Phase $1 \quad$ : 6619

Total Duration for Casting

: 15 months

Number of precast panels to be cast per day : 18

Cycle Time

No.of Moulds provided

$: 1$ day

$: 18$ 
Casting Yard planned with dimensions of $90 \mathrm{~m} \times 20 \mathrm{~m}$ in plan with 2 nos of gantryof $20 \& 10$ ton capacity provided to handle precast elements. The casting yard is proposed to be equipped with moulds to cast the elements are in two rows. Straight panels are cast one side and corner panels are cast on the other side. Reinforcement cage are fabricated in main reinforcement yard and transported through trailer and stacked in Reinforcement stack bed at yard. There is a curing bay which can also be used for stacking depending on quantity of panel cast and a drive way for movement of heavy vehicles. The straight wall and corner panels are stacked vertically with stacking frame.
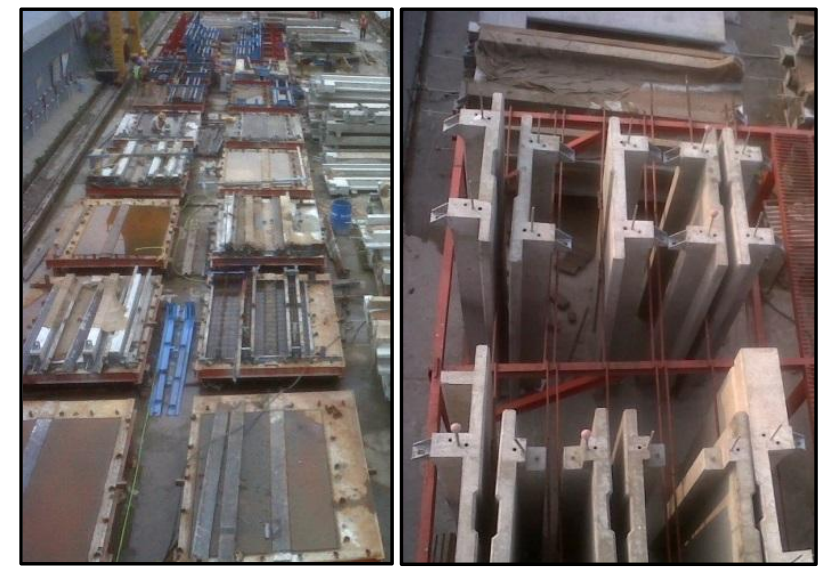

Fig -5: Casting /Stacking at Yard

\subsection{Concrete Placing}

Placing and compacting of fresh concrete carried out under proper supervision using Gantry with concrete bucket directly on the mould and compacted using mould vibrator. Sufficient space provided between the mould bay and stacking bay for transit mixer movement, also special care taken to avoid slurry leakage by providing chamfer on the corners of the mould.

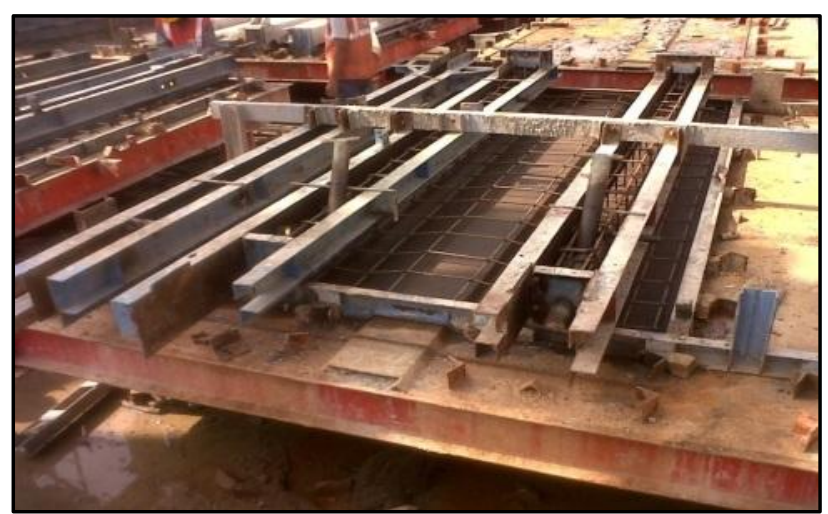

Fig -6: Precast Mould

\subsection{Handling}

The handling process encompasses the demoulding of the precast elements, their loading and transportation to stacking areas, offloading, stacked and then transfer to site for erection.

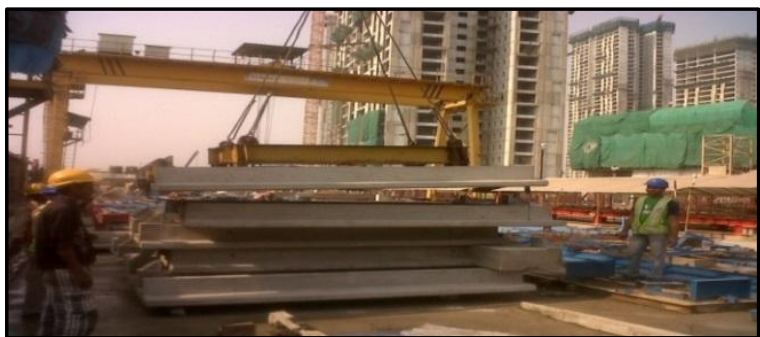

Fig -7: Typical Handling Arrangement at Yard

The precast panels are de-moulded once the concrete achieved sufficient strength to with stand the stresses due to the demoulding process and initial lifting. Strength is assessed by cube tests before de-moulding.

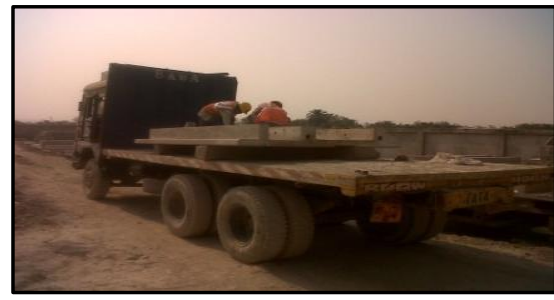

Fig -8: Transportation of precast Panels

The minimum concrete strength at which precast elements lifted from the mould determined by the magnitude of the concrete stresses at the lifting points. To avoid excessive stresses and possible damage, all precast elements are handled in the manner as envisaged in the design as planned and approved by engineer.

\section{ERECTION}

Planning erection for a height of $162 \mathrm{~m}$ was challenging aspects as it has to negotiate various activities which involves for the structure construction.

First and fore most was the selection of tower crane for erection as the max weight of the panel was in the corner of the building (shape of building in $\mathrm{Z} \& \mathrm{H}$ shapes), which decides the selection of Tower crane.

For construction of structure using aluminum formwork, the external platform was used for workmen access; this was hindering the erection process as the sling of the tower crane not approachable near the building hence different type of cantilever strong back has been designed to erect the panel.
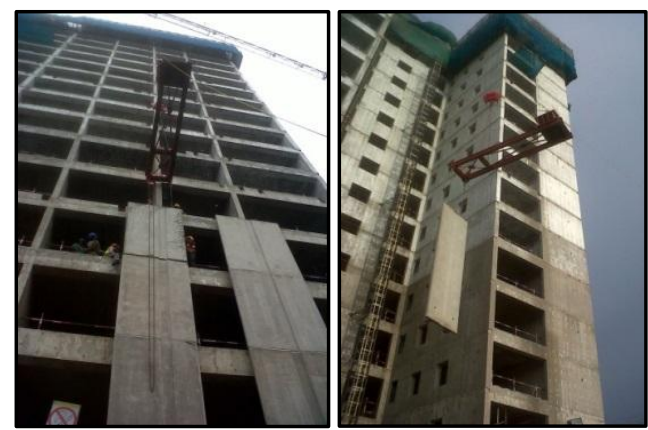

Fig -9: Erection Using Cantilever strong back 
The access for erection of the panel in the corner also was difficult as the panel to be erected in the shear wall .Special working platform was used for the corner panel erection.

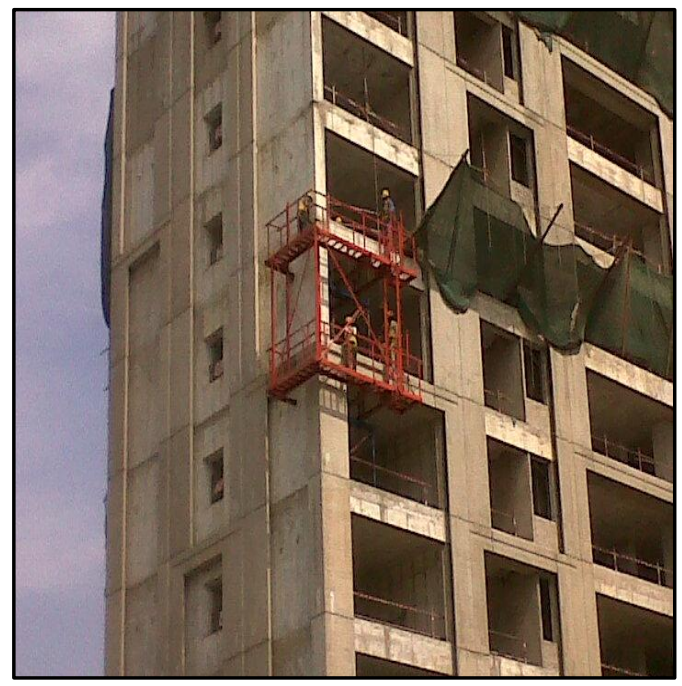

Fig -10: Working Platform for Corner Panels

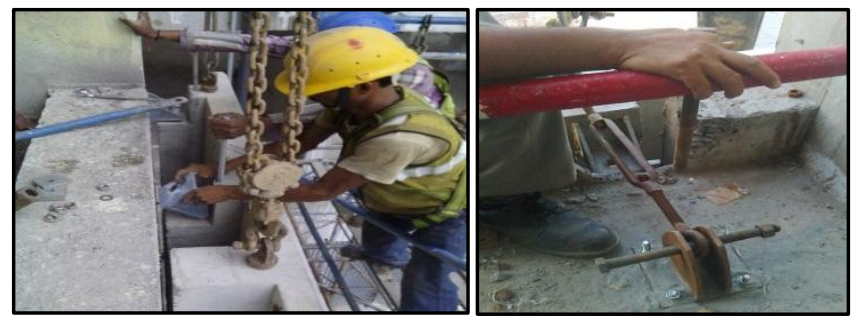

Fig -11: Bracket Fixing \& Alignment

Different Alignment and Grouting procedures have been followed as the connection details varies based on the location on the structure.

Proper verticality and alignment done by using the TurnBuckle and Survey check done to ensure the alignment. The temporary props and turn buckle removed as soon as the grout attains the minimum strength of $25 \mathrm{MPa}$. For next panel erection, at most care has been taken to match the central and horizontal grooves.

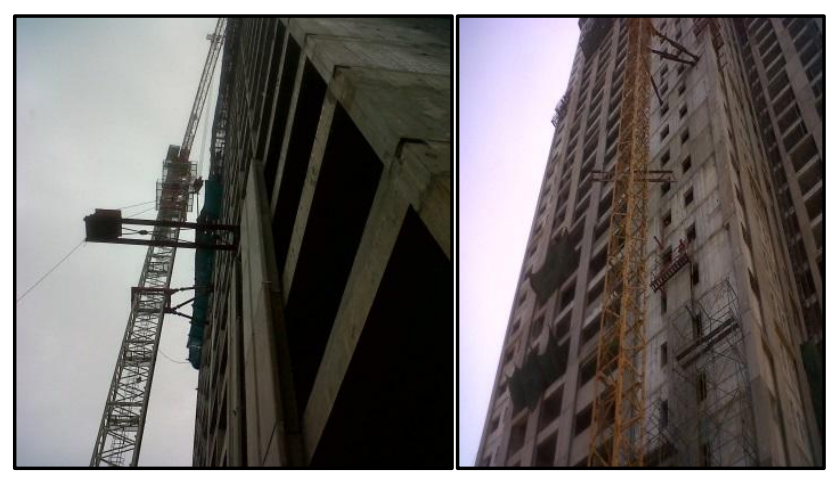

Fig -12: Tower crane Anchorage b/w precast panels

The location of the tower crane has been decided based on the anchorage location and max weight of the element in the corner and avoiding the anchorage in the panel location as the erection of the panel at later stage may not be possible as the panel were erected one over the above

After the erection these panels need to be sealed with sealant which was carried using the rope suspended working platform (RSP) and Mast Climbing Working Platform (MCWP) after the structure completes.
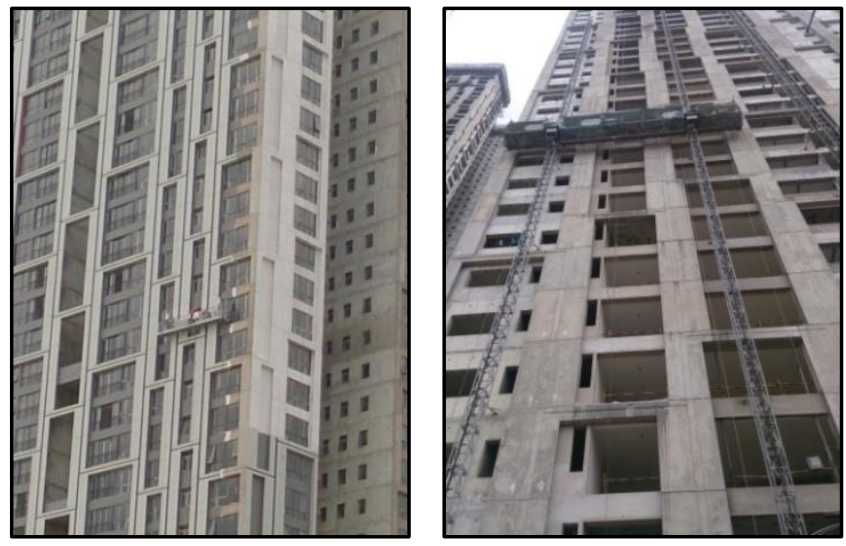

Fig -13: RSP/MCWP for Finishing Works

Adopting the above methodology at peak completed panel erection for a single tower in three months.

\section{CONCLUSIONS}

To achieve architectural features for high rise building, precast technology is the only solution to address the project duration and with diminishing skilled workmen force. Indian construction industry is conventional in nature requires modern technology approach to deliver the project in stringent duration. For repetitive activities, mass volume in shorter duration precast technology is apt technology to adopt. Day by day demand in infrastucture in India is increasing, to meet such demand precast technology paves way for future.

\section{REFERENCES}

[1]. IS15916(2011) - Building design and erection using Prefabricated concrete -Code of practice

[2]. IS 15917 (2010) - Building design and erection using mixed / composite construction - Code of practice

[3]. IS 11447 (1985) - Code of practice for construction with large panel prefabricates

\section{BIOGRAPHIES}

Post Graduate in structures with field experience of 20years, in L\&T as Head of Construction methods planning for residential buildings \& factories. Provided methods for landmark buildings in India. Good knowledge in latest construction technology, precast methods and high rise building construction, trouble shooting at construction site and expertise in selection of right Site logistics, Suitable formwork, Plant and Machineries ,erection scheme for structural steel and shoring system for deep excavation. 